\title{
Review of Recent Developments in Leadership Theories
}

\author{
Kossivi Bodjrenou, Ming Xu \\ Glorious Sun School of Business and Management, Donghua University, Shanghai, China \\ Email: kossbodj@gmail.com
}

How to cite this paper: Bodjrenou, $\mathrm{K}$. and Xu, M. (2018) Review of Recent Developments in Leadership Theories. Open Journal of Social Sciences, 6, 180-188. https://doi.org/10.4236/jss.2018.67014

Received: June 8, 2018

Accepted: July 28, 2018

Published: July 31, 2018

Copyright $\odot 2018$ by authors and Scientific Research Publishing Inc. This work is licensed under the Creative Commons Attribution International License (CC BY 4.0).

http://creativecommons.org/licenses/by/4.0/

\begin{abstract}
Due to its importance to an organization, leadership has been one of the hottest topics in organizational science for decades, resulting in a proliferation of theories. To account for recent development of leadership theories, we conducted a review of the literature on the subject that covers the past 15 years (2002-2017). This paper aims at studying new development in leadership theory such as evolutionary leadership, the relationship between personality traits and leadership styles, and leadership culture, questioning their practicality, and giving directions for future research. Our review was carried out from a relational perspective: Leader-member relationship and individual-organization relationship. Having in view the evolutionary theory, we observed similarities between the five levels of leadership, leadership styles and types of organization culture.
\end{abstract}

\section{Keywords}

Leadership Style, Personality Traits, Evolutionary Leadership, Organizational Culture, Leadership Culture

\section{Introduction}

An increase interest of the subject by researchers has been observed for decades and this seems not to slow down [1]. Prior to the current decade Gardner and colleagues noted an exponential rise of scholarly research related to leadership [2]. The rise of leadership theories during the last decade [1] is evidence of its importance. The importance of leadership to the organization can be examined from the perspective of leadership culture.

Leadership is vital to an organization's success and has a significant influence on its financial performance. As such many leadership studies observed that an organization is dependent upon the ability of its managers to lead. Wang and colleagues observed that over a century of leadership research has consistently 
established that organization's efficiency is strongly dependent on leadership quality [3]. The choice of a CEO is as vital as the choice of the industry in which the company operates. Both decisions account for $15 \%$ variance in the business entity's profitability [4].

Organizational culture, defined as a means of creating significant competitive advantage [5] [6] can be shaped through leadership. Leaders can define behavioral standards or norms that guide individual or collective conduct in an organization [7]. Leadership can also define the values of an organization [8]. Leadership ensures harmony and cohesion of the organization and guarantees goal congruence [9].

The field of leadership is complex and requires a multi-level analysis to better comprehend the phenomenon [10]. According to Wang and Howell, the concept of leadership is not simple and to grasp the phenomenon a deeper analysis is needed [11]. DeRue and colleagues also regarded leadership as a compound concept that necessitates multiple mediating and moderating factors for a better understanding [12]. Dinh and colleagues observed that traditionally leadership studies focus on the analysis at a personal, dyadic, group, and organizational levels [1]. The present review covers leadership at relational and organizational levels taking into account the evolutionary view. Evolutionary Leadership is a dynamic and an unending process of learning where leaders constantly push their boundaries and those of their followers to achieve a higher vision they connected with [13].

\section{Leader-Member Relationship and Personality}

People are different and effective leaders do not lead them the same way [14]. This poses a need for leaders to know their followers. Good leaders do not lead everyone the same way because every person is different, and you are not on the same level of leadership with every person. In an attempt to help leaders know members more, Anderson et al. (2017), examines followers from generational differences perspective [15]. They observed that the new generation, in addition to being increasingly individualistic, is more interested in work-life balance and extrinsic rewards. To fill these generational gaps, they came out with a number of recommendations such as preselection, Realistic Job Previews (RJP) and Expectation Lowering Procedures (ELP), socialization, performance, appraisal, education and training of managers, and reverse mentorship. Hybels (2016) viewed leadership as a leader-follower relationship to achieve a common goal [16] and a considerable number of studies observed that a quality relationship between colleagues and supervisors at the workplace reduces stress, turnover intentions and increases job satisfaction and performance [17] [18]. This observation calls for the following question: how do leaders and followers build and maintain relationships? Previous studies on the subject matter examined the relationship only from an employee perspective giving all the attention to the management of their careers, but the development of the relationship should be 
examined from both perspectives [19]. In an attempt to fill this gap, Nahrgang and colleagues established that the development of relationship at the initial stage is determined by the agreeableness of the leader and the extraversion of the member. They also observed that at a deeper stage, performance of both the member and the leader becomes a predictor of the quality of their relationship. They came out with the observation that extraversion and agreeableness are important factors in the development of leader-member relationship particularly at the early stage. The period of experiment seems too short and the research was not conducted in a real-life situation like the workplace.

The personality factors analysis was extended by others research. Ozbag (2016) extended the personality factors to five by adding to extraversion and agreeableness, Neuroticism, Openness to Experience, and Conscientiousness but restricted the scope of the research to ethical leadership [20]. As opposed to the work of Nahrgang, Morgeson, \& Ilies (2009), the study only looked at the relationship from one perspective, how followers perceive their leaders, and observed that neuroticism negatively correlates with ethical leadership, while agreeableness is positively associated with it. No significant association of extraversion and ethical leader was noted but conscientiousness was associated with it. Ozbag (2016) did not successfully link the findings to practical implications and his experiment is not a field study. Field studies carry more credibility and their relevance in real-life situations is less questionable.

Many scholars expanded the scope of leadership styles and studied their relationship with personality traits but found weak links. For de Vries (2012) found the explanation in the low level of self-other agreement among leaders and followers [21]. Extraversion, Conscientiousness, and Openness to Experience have been associated to leadership emergence and effectiveness [22]. However, many studies concluded that the Big Five-Factor Model cannot accurately predict transformational and transactional leadership [12]-[23]. De Vries (2012) used the HEXACO model [24] and observed that personality is a significant correlate of leadership styles [21]. However, he seemed not to have considered the evolutionary theory of personality and ultimately leadership style.

Different personality types have been associated with different leadership styles and evolutionary psychology approaches personality from an adaptive perspective based on circumstances. How about leadership in which the style has been correlated with personality? Can the leadership of an individual also evolve over time based on the situations?

\section{Evolutionary Leadership}

Leadership has been recently approached from an evolutionary perspective [25]. Contrary to other leadership theories, Evolutionary Leadership is a dynamic and an unending process of learning where leaders constantly push their boundaries and those of their followers to achieve a higher vision they connected with [13]. Evolutionary leaders are models committed to transform their person, followers 
and the organization as a whole. Maxwell (2011) seems to share the evolutionary theory viewpoint and identified five levels that every leader has go through in their leadership development from Positional Level to Pinnacle Level which only those naturally gifted with leadership can reach [14]. At the Relational Level, where the leader builds relationship with members who then become followers, could be associated with agreeableness. At the Production Level, leaders have to exhibit more of task-oriented leadership style which has been associated to the personality trait of conscientiousness [21]. At the People Development Level, leaders need to show characteristics of a Charismatic Leadership style such as energy, expressiveness and social confidence [21]. That are expressions of Extraversion personality-trait.

Studies mentioned above focused on individuals but how have leadership and organization as a whole been linked recently? We will answer this question from an organizational culture standpoint because of its influence on all employees and the processes across the organization, as well as the fact that it is one of the most examined in management science [5].

\section{Leadership and Organization Culture}

Organization culture is a broad and complex issue that comprises of shared values, attitudes, beliefs, assumptions, artifacts and behaviors. Culture is a predictor of organization success [6]. Tharp (2009) identified four types organization culture: control, compete, collaborate, and create [26]. The control type of culture is internally focused and characterized by bureaucracy, standardization, hierarchy, control and monitoring of people and processes. Here internal organization is a key success factor for the organization. The compete-type is outwardly oriented and focuses on building good relations with suppliers, customers, contractors, legislators, regulators, and on competiveness and productivity. In the collaborate type of culture team cohesion is valued, the organization tends to believe that there is strength in numbers and acts like an extended family driven by ethics and high morale. An organization with create type of culture promotes innovation and creativity and tends to be flexible and can easily adapt to change. Tharp (2009) is of the view that no organization culture is better than the other and depending on the circumstance some cultures might be more suitable. This study tends to view culture from a static perspective. However, organization culture can be subject to intentional alteration or can evolve [6]. As mentioned above, culture and leadership has been viewed by many researchers as key factors for organization success. This leads to the following question: can culture and leadership be combined to achieve greater organization success?

Actually, leadership has also been studied from a cultural perspective and has been termed leadership culture [14]. "Leadership Culture exists when leaders are routinely and systematically developed, and you have a surplus of leaders" [6]. According to Hogg (2016), in leadership culture, the entity purposely invests resources to develop leaders not only within senior management but across the 
whole organization [27]. For the Center for Creative Leadership (2017), it is "the self-reinforcing web of beliefs, practices, patterns and behaviors. It's the way things are done, the way people interact, make decisions and influence others" [28].

Miller (2017) perceived leadership as the "only sustainable competitive advantage" and "the cornerstone of all great organizations" [6]. However, leadership cannot be effective unless it is rooted in the culture of the organization. This is the reason why he said a culture that ensures the consistent development of leaders places the organization in a winning position [6]. For Maxwell (2011) the effectiveness of leadership is assessed, not only on the attainment of objectives, but by how much the leader gets things done through leaders he has raised [14]. Through developing leaders, sustainable growth can be achieved. Hogg (2016) defined five steps in creating leadership culture which are in a progressive order: definition of culture, leadership culture into hiring, accountability in leadership development, exposure to decision making through coaching and mentoring, and professional skills development across the organization [27]. He is of the view that the responsibility to create leadership culture rests upon senior executives. Hogg (2015) pointed out five things effective leaders do to create leadership culture: clearly define the purpose, walk the talk, practice self-awareness, recognize the value of people, and create transformative organizational change [29]. Miller (2007) identified five keys to creating leadership culture: define, train, practice, measure and model [6]. This a simplistic way of viewing organization culture which is itself a complex concept in such that it is uniform across the whole organization but there can be, for instance, departmental cultures [26].

\section{Findings}

Our review enabled us to draw some similarities between the five levels of leadership [14], leadership styles and types of organization culture [26] all based on the evolutionary theory [25]. This is summarized in the Table 1 below.

At the Position Level, leaders rely on "rules, regulations, policies, and organization charts to control their people" [14]. This seems to describe an autocratic

Table 1. Comparison of individual and organizational leadership development.

\begin{tabular}{ccccc}
\hline $\begin{array}{c}\text { Evolutionary } \\
\text { Leadership } \\
\text { (Van Vugt })\end{array}$ & $\begin{array}{c}5 \text { Levels of Leadership } \\
\text { (Maxwell) }\end{array}$ & Leadership Style & Personality Traits & $\begin{array}{c}\text { Organization } \\
\text { Culture (Tharp) } \\
\text { Organization }\end{array}$ \\
\cline { 3 - 5 } & Pinnacle & Transformational & $?$ & $?$ \\
& $\begin{array}{c}\text { PeopleDevelopment } \\
\text { Production }\end{array}$ & Charismatic & Extraversion & Create \\
& Permission & Supportive & Agreeableness & Collaborate \\
& Position & Autocratic & Conscientiousness & Compete \\
& & & & Control \\
& & & &
\end{tabular}


leader when looked at from organization viewpoint, it bears similarities with the control-type of culture [26]. At the Permission Level, leaders build relationship, trust, and an agreeable working environment [14]. This description is close to collaborate-type of culture and supportive leadership which has been associated with agreeableness [21]. At the Production Level, leaders "get things done!" and the emphasis is on performance. This picture seems to paint compete-type of organization culture, where results matter and task-oriented leadership of which conscientiousness is the predictor [21]. At the People Development Level, leaders empower and raise other leaders [14]. This portrays charismatic leadership to which extraversion has been associated [21]. Empowerment of potential leaders calls for the need to give them the opportunity to create and innovate, and for this reason we associate create-type of organization culture with People Development. At the Pinnacle Level, the reputation of the leader "transcends their position, their organization, and sometimes their industry" [14]. This depicts transformational leadership.

\section{Practical Implications}

Doing things casually or randomly barely leads to achievement but when things are done on purpose and with intentionality, effectiveness and efficiency are increased [14]. Furthermore, there is a need to measure or quantify progress towards achievement of a defined goal [6]. Our research suggests intentionality and measurability in leadership development for both individuals and organizations. Taking the evolutionary viewpoint, we extended the five levels of leadership [14] by identifying at each stage the leadership styles that both individuals and organizations are to exhibit in order to increase the effectiveness of their leadership. It is important to take note that results cannot be achieved without cohesion, which cannot be built without relationship. For relationship to spring there must be agreement. Therefore there is a need for the organization and leadership to bring on board people with vision similar to that of the group. This calls for clarity of vision which is the starting point because without it there cannot be comparison of visions. Through their good performance individuals show that in actual fact their vision is the same as that of the organization and qualifies to be assigned a greater responsibility. Effective leaders will ascend to the next level that is the development of leaders, where they train others to become like them.

We proposed a systematic approach to leadership culture development based on the five levels of leadership and correlate them to leadership style to enable leaders and organizations assess the effectiveness of their leadership and help them to be more intentional about their ascension.

\section{Direction for Future Research}

De Vries (2012) established that agreeableness, conscientiousness and extraversion significantly correlate respectively with supportive, task-oriented, and cha- 
rismatic leadership styles [21]. We observe in our research that the "Position Level" and the "Pinnacle Level" reflect respectively autocratic and transformational leadership styles. However, the correlation between these two leadership styles with personality traits has not clearly been established as it is for supportive, task-oriented, and charismatic leadership styles.

Our review enabled us to establish a relationship between leadership styles and organization culture. We connected Autocratic, Supportive, Task-oriented, and Charismatic leadership styles respectively with Control, Collaborate, Compete, and Create cultures. However, the question "to which culture-type can transformational leadership can best be associated?" is still unanswered

\section{Conclusion}

In conclusion, instead of being static, leadership is a corporate journey to reach a shared destination. For this matter it requires from leaders and organizations intentionality, the capacity for development to move to the top, and the ability to measure progress towards the defined common goal. Though individuals have their personalities and organization their cultures, both can evolve. Further studies could find the personality traits that best correlate autocratic and transformational leadership styles and the type of organization culture that can be associated with transformational leadership.

\section{Comment to the Author}

This paper aims at studying new development in leadership theory such as evolutionary leadership, the relationship between personality traits and leadership styles, and leadership culture, questioning their practicality, and giving directions for future research.

\section{Conflicts of Interest}

The authors declare no conflicts of interest regarding the publication of this paper.

\section{References}

[1] Dinh, J.E., Lord, R.G., Gardner, W. L., Meuser, J.D., Liden, R.C. and Hu, J. (2014) Leadership Theory and Research in the New Millennium: Current Theoretical Trends and Changing Perspectives. The Leadership Quarterly, 21, 922-958.

[2] Gardner, W.F., Cogliser, C.C., Davis, K.M. and Dickens, M. (2011) Authentic Leadership: A Review of the Literature and Research Agenda. The Leadership Quarterly, 22, 1120-1145. https://doi.org/10.1016/j.leaqua.2011.09.007

[3] Wang, H., Tsui, A.S. and Xin, K.R. (2011) CEO Leadership Behaviors, Organizational Performance, and Employees' Attitudes The Leadership Quarterly, 22, 92-105. https://doi.org/10.1016/j.leaqua.2010.12.009

[4] Nohria, N., Joyce, W. and Roberson, B. (2003) What Really Works. [Electronic Version]. https://www.researchgate.net/publication/10662988_What_Really_Works

[5] Mohelska, H. and Sokolova, M. (2015) Organizational Culture and Leader- 
ship-Joint Vessels? Social and Behavioral Sciences, 171, 1011-1016.

[6] Miller, M. (2017) Leaders Made Here. 1st Edition, Berrett-Koehler Publishers.

[7] Mayer, D.M., Kuenzi, M., Greenbaum, R., Bardes, M. and Salvador, R.B. (2009) How Low Does Ethical Leadership Flow? Test of a Trickle-Down Model. Organizational Behavior and Human Decision Processes, 108, 1-13. https://doi.org/10.1016/j.obhdp.2008.04.002

[8] Brown, M.E. and Treviño, L.E. (2009) Leader-Follower Vales Congruence: Are Socialized Charismatic Leaders Better Able at Achieve It? Journal of Applied Psychology, 94, 478-490. https://doi.org/10.1037/a0014069

[9] Fry, L.W. (2003) Toward a Theory of Spiritual Leadership. The Leadership Quarterly, 14, 693-727. https://doi.org/10.1016/j.leaqua.2003.09.001

[10] Cho, J. and Dansereau, F. (2010) Are Transformational Leaders Fair? A Multi-Level study of Transformational Leadership, Justice Perceptions, and Organizational Citizenship Behaviors. The Leadership Quarterly, 21, 409-421. https://doi.org/10.1016/j.leaqua.2010.03.006

[11] Wang, X.H. and Howell, J.M. (2010) Exploring the Dual-Level Effects of Transformational Leadership on Followers. Journal of Applied Psychology, 95, 1134-1144. https://doi.org/10.1037/a0020754

[12] DeRue, D.S., Nahrgang, J.D., Wellman, N. and Humphrey, S.E. (2011) Trait and Behavioral Theories of Leadership: An Integration and Meta-Analytic Test of Their Relative Validity. Personnel Psychology, 64, 7-52. https://doi.org/10.1111/j.1744-6570.2010.01201.x

[13] Freifeld, L. and Busser, D. (2013) Evolutionary Leadership: How to Recognize and Nurture It to Avoid Extinction. [Electronic Version]. https://trainingmag.com/content/evolutionary-leadership

[14] Maxwell, J.C. (2011) The Five Levels of Leadership: Proven Steps to Maximize Your Potential. 1st Edition, Hachette Book Group.

[15] Anderson, H.J., Baur, J.E., Griffith, J.A. and Buckley, M.R. (2017) What Works for You May Not Work for (Gen)Me: Limitations of Present Leadership Theories for the New Generation. The Leadership Quarterly, 28, 245-260.

[16] Hybels, B. (2016) Leading from Here to There: Five Essential Skills. Zondervan.

[17] Humphrey, S.E., Nahrgang, J.D. and Morgeson, F.P. (2007) Integrating Motivational, Social, and Contextual Work Design Features: A Meta-Analytic Summary and Theoretical Extension of the Work Design Literature. Journal of Applied Psychology, 92, 1332-1356. https://doi.org/10.1037/0021-9010.92.5.1332

[18] Ilies, R., Nahrgang, J.D. and Morgeson, F.P. (2007) Leader-Member Exchange and Citizenship Behaviors: A Meta-Analysis. Journal of Applied Psychology, 92, 269-277. https://doi.org/10.1037/0021-9010.92.1.269

[19] Nahrgang, J.D., Morgeson, F.P. and Ilies, R. (2009) The Development of Leader-Member Exchanges: Exploring How Personality and Performance Influence Leader and Member Relationships over Time. Organizational Behavior and Human Decision Processes, 108, 256-266. https://doi.org/10.1016/j.obhdp.2008.09.002

[20] Ozbag, G.K. (2016) The Role of Personality in Leadership: Five Factor Personality Traits and Ethical Leadership. Social and Behavioral Sciences, 235, 235-242.

[21] De Vries, R.E. (2012) Personality Predictors of Leadership Styles and the Self-Other Agreement Problem. The Leadership Quarterly, 23, 809-821.

https://doi.org/10.1016/j.leaqua.2012.03.002 
[22] Judge, T.A., Bono, J.E., Ilies, R. and Gerhardt, M.W. (2002) Personality and Leadership: A Qualitative and Quantitative Review. Journal of Applied Psychology, 87, 765-780. https://doi.org/10.1037/0021-9010.87.4.765

[23] De Hoogh, A.H.B., Den Hartog, D.N. and Koopman, P.L. (2005) Linking the Big Five-Factors of Personality to Charismatic and Transactional Leadership: Perceived Dynamic Work Environment as a Moderator. Journal of Organizational Behavior, 26, 839-865. https://doi.org/10.1002/job.344

[24] Lee, K. and Ashton, M.C. (2008) The HEXACO Personality Factors in the Indigenous Personality Lexicons of English and 11 Other Languages. Journal of Personality, 76, 1001-1053. https://doi.org/10.1111/j.1467-6494.2008.00512.x

[25] Van Vugt, M. (2006) Evolutionary Origins of Leadership and Followership. Personality and Social Psychology Review, 10, 354-371.

https://doi.org/10.1207/s15327957pspr1004_5

[26] Tharp, M.B. (2009) Four Organizational Culture Types. http://faculty.mu.edu.sa/public/uploads/1360757023.3588organizational\%20cult98. pdf

[27] Hogg, B. (2016) Five Steps to Create a Culture of Leadership. http://www.billhogg.ca/2016/11/5-steps-to-create-a-culture-of-leadership/

[28] Center for Creative Leadership (2017) What's Your Leadership Culture? https://www.ccl.org/articles/leading-effectively-articles/whats-your-leadership-cultu re/

[29] Hogg, B. (2015) Five Things All Great Leaders Do to Create a Culture of Leadership.

http://customerthink.com/5-things-all-great-leaders-do-to-create-a-culture-of-leade $\underline{\text { rship/ }}$ 